\title{
CAPACIDADES DINÂMICAS E ESTRATÉGIAS PARA ENFRENTAMENTO DA CRISE DIANTE DA PANDEMIA DA COVID-19
}

\section{DYNAMIC CAPABILITIES AND STRATEGIES FOR COPING WITH THE COVID-19 PANDEMIC CRISIS}

\author{
ANA CLÁUDIA WECKER \\ Universidade Feevale \\ Mestranda do PPG em Administração da Universidade Feevale \\ Orcid: http://orcid.org/0000-0001-7905-7242 \\ E-mail: anawecker@feevale.br \\ Rodovia RS 239, 2755 - Novo Hamburgo / RS, CEP: 93525-075
}

\section{CRISTIANE FROEHLICH}

Universidade Feevale

Docente do PPG em Administração da Universidade Feevale

Orcid: http://orcid.org/0000-0001-7198-6469

E-mail: cristianefroehlich@hotmail.com

\section{MANUELA ALBORNOZ GONÇALVES}

Universidade Feevale

\author{
Doutora em Administração pela Universidade Federal do Rio Grande do Sul (UFRGS) \\ Orcid: http://orcid.org/0000-0002-1536-6377 \\ E-mail: manuelaag@feevale.br
}

\begin{abstract}
Submissão: 06/08/2020. Revisão: 03/10/2020. Aceite: 05/11/2020. Publicação: 29/12/2020. DOI: http://dx.doi.org/10.22277/rgo.v14i1.5711
\end{abstract}

\section{RESUMO}

A teoria das capacidades dinâmicas aborda a reconfiguração e o desenvolvimento de competências organizacionais em face a intensas mudanças, observando ambiente e recursos organizacionais. Com a descoberta da síndrome respiratória SARS-CoV-2 surge a pandemia da COVID-19, afetando a economia global e gerando um cenário de incertezas para as organizações. O presente artigo tem como objetivo identificar as estratégias de enfrentamento da crise diante da pandemia da COVID-19 sob a lente das capacidades dinâmicas. Para tanto, realizou-se estudos de caso múltiplos em dez empresas da região metropolitana de Porto Alegre, no Rio grande do Sul, pesquisa do tipo descritiva, com abordagem qualitativa. A pesquisa apresenta as ações das empresas para enfrentamento da crise diante da pandemia e relaciona com os microfundamentos que sustentam as capacidades dinâmicas: sensing, seizing e reconfiguring. Os resultados evidenciam que as capacidades dinâmicas tendem a contribuir neste contexto, através da identificação de oportunidades e ameaças, aproveitamento de oportunidades e reconfiguração de rotinas. 0 estudo identifica práticas das empresas relacionadas a cada um dos microfundamentos, bem como sugestões com base na literatura. Verificou-se que as empresas estudadas ainda podem desenvolver suas capacidades dinâmicas, principalmente no que se refere ao microfundamento reconfiguring.

Palavras-chave: Capacidades dinâmicas. COVID-19. Estratégia. 


\begin{abstract}
The theory of dynamic capabilities addresses the reconfiguration and development of organizational skills in the face of intense changes, observing organizational environment and resources. With the discovery of the SARS-CoV-2 respiratory syndrome, the COVID-19 pandemic arises, affecting the global economy and creating a scenario of uncertainty for organizations. This article aims to identify strategies for coping with the crisis in the face of the COVID-19 pandemic under the lens of dynamic capabilities. For this purpose, multiple case studies were carried out in ten companies in the metropolitan region of Porto Alegre, in Rio Grande do Sul, a descriptive research with a qualitative approach. The research presents the actions of companies to face the crisis in the face of the pandemic and relates to the microfoundations that support dynamic capabilities: sensing, seizing and reconfiguring. The results show that dynamic capabilities tend to contribute in this context, by identifying opportunities and threats, taking advantage of opportunities and reconfiguring routines. The study identifies company practices related to each of the micro-foundations, as well as suggestions based on the literature. It was found that the companies studied can still develop their dynamic capabilities, especially about reconfiguring microfunding.
\end{abstract}

Keywords: Dynamic Capabilities. COVID-19. Strategy.

\title{
1 INTRODUÇÃO
}

Crises globais, desastres naturais, concorrências e novas tecnologias são contextos que exigem rápidas adaptações e mudanças de estratégias por parte das empresas (GIROD; WHITTINGTON, 2017). São situações que provocam a necessidade de reação organizacional para manutenção dos negócios.

A abordagem sobre capacidade dinâmica (CD) é uma das teorias que explicam estes processos de rápidas adaptações e mudanças organizacionais, através da reconfiguração organizacional e desenvolvimento de competências, observando o ambiente e os recursos organizacionais.

Entretanto, apesar de o conhecimento sobre o tema ter evoluído com o decorrer dos anos, ainda existe falta de consenso entre os autores em suas diversas abordagens (GUERRA; TONDOLO; CAMARGO, 2016). Alguns autores concentram sua análise nos aspectos internos da organização (EISENHARDT; MARTIN, 2000; COLLIS, 1994; TEECE 2007). Outros associam ao dinamismo do ambiente (TEECE; PISANO; SHUEN, 1997; WANG; AHMED, 2007). Há ainda aqueles que se concentram na trajetória, mecanismos e dispositivos que configuram as capacidades dinâmicas (ZOLLO; WINTER, 2002).

No ano de 2020, observou-se uma crise global como consequência da COVID-19 e de sua principal estratégia de enfrentamento - o isolamento social. De um dia para o outro, empresas e consumidores tiveram que se adaptar e reagir rapidamente ao novo cenário imposto. Às empresas coube o desenvolvimento e a realização de estratégias de enfrentamento.

Diante deste contexto, entender quais estratégias de reconfiguração organizacional, quais competências organizacionais, e quais os recursos organizacionais foram utilizados na gestão e adaptação organizacional é importante, pois possibilitará uma preparação mais serena a novas situações como esta e insights para outras empresas. Ainda, uma organização que é capaz de otimizar suas competências e recursos em um momento como este, poderá aproveitar esses mesmos recursos e competências em situações de maior estabilidade. 
Em 31 de dezembro de 2019, iniciaram as descobertas sobre o novo Coronavírus, uma família de vírus que causa infecções respiratórias e provoca a doença chamada COVID-19, sendo os primeiros casos identificados na China (WU et al., 2020). Em um curto período, a doença se espalhou por diversos países. No Brasil, o primeiro caso foi diagnosticado em 25 de fevereiro de 2020, através de um brasileiro que havia viajado para a Itália, região onde o surto também estava presente.

Em 11 de Março de 2020, o diretor-geral da OMS, Tedros Adhanom Ghebreyesus, caracterizou a situação como uma pandemia, com mais de 118 mil casos em 114 países e 4.200 mortos, solicitando aos países que tomassem medidas urgentes para suprimir e controlar a situação (OPAS, 2020). Como consequência das medidas adotadas uma crise econômica teve início (NICOLA et al., 2020).

A recessão que acompanha a pandemia de Covid-19 tende a levar a picos de desemprego e perda de renda, especialmente, entre os países que já estão em posições precárias. Após a crise financeira internacional de 2008, essa tende a ser uma nova crise a afetar os negócios. De acordo com o boletim da OMS de 14 de março de 2020, o Rio Grande do Sul (RS), nesta data, já possuía mais de 2.000 casos notificados. A região metropolitana de Porto Alegre, onde se localizam as empresas estudadas neste artigo, contempla 34 municípios do Rio Grande do Sul, nela se concentra $37 \%$ da população e $44 \%$ do Produto Interno Bruto (PIB) do estado (FEDOZZI; SOARES, 2015).

O gerenciamento de crises globais, onde se lida com o imprevisível e se tem graves consequências, podem gerar grandes dificuldades para as empresas (CORTEZ; JOHNSTON, 2020). Neste contexto, de ambientes turbulentos, as capacidades dinâmicas são valiosas, já que possibilitam maior capacidade de resposta para lidar com mudanças, além de aumentar significativamente o desempenho inovador de uma empresa (HAARHAUS; LIENING, 2020).

Alguns autores também enfatizam que as capacidades dinâmicas são usuais em ambientes dinâmicos e incertos (EISENHARDT; MARTIN, 2000; ZAHRA et al., 2006). São sustentadas por microfundamentos (sensing, seizing e reconfiguring) que impulsionam 0 comportamento das organizações, através da identificação, aproveitamento e reconfiguração dos seus ativos, como resposta a ambientes turbulentos (FELIN et al., 2012). Também, sabese que fortes capacidades dinâmicas são essenciais diante de economias interdependentes que experimentam rápidas mudanças tecnológicas e rupturas financeiras (TEECE; LEIH, 2016).

Logo, o problema de pesquisa desse estudo consiste em: de que forma a lente das capacidades dinâmicas auxilia na definição de estratégias para enfrentamento da crise diante da pandemia da COVID-19? Para responder a esta questão, tem-se o objetivo: identificar as estratégias de enfrentamento da crise diante da pandemia da COVID-19 sob a lente das capacidades dinâmicas.

Trata-se de estudos de caso múltiplos, tendo como objeto de pesquisa dez empresas situadas na Região Metropolitana de Porto Alegre, no estado do Rio Grande do Sul, de diversos segmentos e portes (micro, pequena e média). A maioria dos estudos empíricos sobre capacidades dinâmicas se concentram em grandes empresas, logo um estudo empírico com diversidade de portes e segmentos contribui para a aplicação da teoria de capacidades dinâmicas nestes contextos pouco analisados. Ressalta-se, também, a importância que empresas de micro, pequeno e médio portes exercem na economia brasileira (RIBEIRO; CORREA; SOUZA, 2012).

A coleta de dados foi realizada através de entrevistas semiestruturadas que seguiram um roteiro dividido em cinco blocos (informações gerais sobre o entrevistado, sobre a empresa, sensing, seizing e reconfiguring) e dados secundários. A análise dos dados ocorreu 
por meio da análise de conteúdo pelas etapas propostas por Bardin (2016), onde os dados foram analisados de acordo com os cinco blocos/categorias citados previamente.

Este estudo pode contribuir para o avanço de pesquisas que relacionam capacidades dinâmicas em micro, pequenas e médias empresas em ambientes de incerteza. Como contribuições empíricas, tende a mostrar às empresas, especialmente, de micro, pequena e médio portes, possibilidades de estratégias para enfrentamento de uma pandemia e crise nos negócios.

\section{ESTRATÉGIA ORGANIZACIONAL E CAPACIDADES DINÂMICAS}

Não há um conceito único de estratégia, há vários significados, diferentes em sua amplitude e complexidade. Alguns autores incluem metas e objetivos como parte da estratégia, enquanto outros fazem distinções claras entre eles (MINTZBERG, 2006). Sua origem está relacionada à atividade militar, como a união de forças contra o inimigo. Com o decorrer dos anos, o tema evoluiu, em suas diversas abordagens, como a observação de falta de padrões de estratégias nas empresas e inserção de consultorias na área até a formalização do planejamento estratégico e inserção na gestão.

Kennet Andrews, professor da Harvard, publicou uma obra de grande relevância e influência para a disseminação do conteúdo de estratégia nas organizações, sendo também responsável pela criação do modelo de análise SWOT, onde se cruza as oportunidades e ameaças externas à organização com seus pontos fortes e fracos (VILLAR; WALTER; BRAUM, 2017).

Em seguida, surgem os diferentes níveis de estratégia: estratégico, tático e operacional. Michael Porter trouxe o conceito das "cinco forças competitivas", introduziu o "modelo das estratégias genéricas" e lançou o conceito de "cadeia de valor". Já Edward Mason e Joe Bain são os pioneiros na análise SCP (Structure-Conduct-Performance), onde o desempenho das empresas depende da estratégia dos compradores e vendedores (SCHNEIDER et al., 2009).

Com a publicação do artigo de Birger Wernerfelt (1984), surge a RBV (Resources-Based View), ou Visão Baseada em Recursos, que considera os recursos internos de uma organização como responsáveis por vantagem competitiva (BARNEY, 1991). No entanto, em seguida, há um avanço nos estudos, quando alguns autores como Priem e Butler (2001) relataram que a RBV é estática por natureza e inadequada para explicar a vantagem competitiva das empresas em ambientes de mudança rápida e imprevisível. A partir disso, surge o conceito de capacidades dinâmicas, abordando como os recursos podem ser criados e renovados em ambientes de mudanças.

Embora algumas referências anteriores ao conceito possam ser encontradas na literatura, é após a publicação do artigo seminal de Teece, Pisano e Shuen (1997) que a visão de capacidades dinâmicas gerou um fluxo crescente de pesquisa (BARRETO, 2010). Estão associadas à habilidade de integrar, construir e reconfigurar competências internas e externas em resposta às rápidas mudanças que ocorrem nos ambientes nos quais as organizações estão inseridas. A essência das CDs e da vantagem competitiva está baseada em: processos (rotinas ou padrões de práticas correntes e aprendizado), posições (ativos, estrutura de governança, base de consumidores e relações externas com fornecedores e parceiros) e trajetória (histórico de decisões e oportunidades tecnológicas e de mercado) (TEECE; PISANO; SHUEN, 1997).

Cabe ressaltar que há diferentes visões de diversos autores sobre o tema. Para alguns, 
as capacidades dinâmicas são os processos organizacionais e estratégicos pelos quais as empresas obtêm novas configurações de recursos à medida que os mercados emergem, colidem, dividem, evoluem e morrem (EISENHARDT; MARTIN, 2000). Ou ainda, é a capacidade da organização criar, estender ou modificar sua base de recursos (HELFAT et al., 2007).

Outros se referem às capacidades para operar, estender, modificar ou criar capacidades comuns (ZOLLO; WINTER, 2002). Também é definida como o comportamento organizacional orientado a integrar, reconfigurar, renovar e recriar seus recursos e capacidades e, ainda, melhorar e reconstruir suas capacidades chave em resposta às mutações do ambiente para atingir e sustentar a vantagem competitiva (WANG; AHMED, 2007).

Em 2007, Teece apresentou um novo conceito onde as capacidades dinâmicas sensing, seizing e reconfiguring são sustentadas por microfundamentos. Sensing refere-se a detectar e moldar oportunidades e ameaças, o que envolve a atividade de procura, criação, aprendizado e interpretação. $O$ investimento em pesquisas, exploração de mercados e tecnologias e captura de ideias de funcionários, contribuem para esta etapa (TEECE, 2007). A coleta de informações sobre clientes também é uma base importante (KINDSTROM; KOWALKOSKI, 2013). Esta identificação de oportunidades e ameaças permite que a organização elabore estratégias de forma a atender tendências de mercado.

Seizing é aproveitar as oportunidades. Esta fase deve ser abordada através de novos produtos, processos ou serviços, investindo em atividades de desenvolvimento e comercialização. Envolve a manutenção e o aprimoramento de competências tecnológicas e ativos complementares (TEECE, 2007). Considera a tomada de decisão e a execução das oportunidades tecnológicas ou mercadológicas, tangibilizadas em produtos ou serviços (MARANZATO; SALERNO, 2018). Além destes aspectos, deve existir um modelo de negócios que sustente e explore novas oportunidades conforme estas surgem (KINDSTROM; KOWALKOSKI, 2013). Esta é uma tarefa desafiadora, que envolve habilidade de investimentos, tomada de decisão e capacidade de assumir riscos.

Reconfiguring pode ser entendido como recombinar e reconfigurar ativos e estruturas organizacionais. $\mathrm{O}$ aproveitamento de oportunidades pode levar ao crescimento e aumento de recursos e ativos da empresa (TEECE, 2007). Para isto, é necessária a reconfiguração e renovação de rotinas, processos gerenciais e incentivos para que a empresa se mantenha e continue evoluindo.

Scherer (2017) verifica aplicações dos microfundamentos das capacidades dinâmicas em rotinas de uma empresa de grande porte. Por exemplo, para o microfundamento sensing, há visitas a clientes, participação em feiras e eventos, pesquisa de mercado, análise da concorrência, campanhas internas para geração de ideias, desenvolvimento de tecnologias em conjunto com universidades, entre outros. Em relação ao microfundamento seizing, consta a análise de viabilidade econômica, plano de lançamento de produto, avaliação de protótipos, avaliação de capacidade física e tecnológica da empresa, plano de capacitação para os colaboradores, entre outros. Já o reconfiguring considera equipes multifuncionais em projetos, banco de ideias, patenteamento e certificações de direitos de propriedade. Por fim, o estudo conclui que as capacidades dinâmicas contribuem para o processo de inovação.

A operacionalização desses microfundamentos ocorre durante a trajetória da organização, a partir da definição de seu posicionamento e da consolidação de processos organizacionais. Diante disso, as capacidades dinâmicas contribuem para inovação já que permitem a apropriação de um estoque de conhecimentos que sustentam o desenvolvimento de outras e diferentes capacidades a serem utilizadas de acordo com a trajetória estratégica da organização (AGUIAR et al., 2020). Os mesmos autores citam como exemplos de ações em 
seu estudo: incentivo ao desenvolvimento de melhorias de processos e novas ideias, identificação de novas tecnologias, parcerias com universidades contribui para o microfundamento sensing. Quanto ao seizing, destacam-se mudanças de produtos e processos, investimentos em ações voltadas para novos projetos e construção de um ambiente interno de lealdade e comprometimento. Já a participação dos funcionários nas tomadas de decisão, gestão do conhecimento e gerenciamento de informações são práticas do microfundamento reconfiguring (AGUIAR et al., 2020).

Em relação ao porte das empresas, as multinacionais e grandes empresas absorvem melhor as mudanças ambientais devido à sua diversidade e variedade de produtos e mercados (FRANK; GUTTEL; KESSLER, 2017). Empresas menores geralmente usam mais as habilidades dos fundadores, ou seja, suas capacidades gerenciais dinâmicas.

A pesquisa sobre capacidades gerenciais dinâmicas enfoca o papel dos gerentes na mudança sistemática da base de recursos (HELFAT; MARTIN, 2015). Só o fato de possuir recursos não garante que uma organização tenha desempenho superior e, por este motivo, é necessária a capacidade gerencial para orquestrar recursos e assim obter vantagem. Pode-se dizer que assim como um regente é essencial para o desempenho de uma orquestra, o gestor é fundamental na orquestração de recursos em uma organização para que se tenha um desempenho superior, especialmente, diante ambientes de incertezas (CHIRICO et al., 2011).

A literatura aponta que micro e pequenas empresas podem ter uma maior limitação de recursos, com menos possibilidades de investimentos. No entanto, sua estrutura reduzida facilita o fluxo de informações e proximidade com clientes e fornecedores, com os quais é necessário gerar relações de valor, orientadas para o trabalho conjunto de inovação e formação de parcerias e alianças estratégicas (MORALES-RUBIANO et al., 2016). Já a gestão da empresa tem uma grande responsabilidade em relação à proposição de dinâmicas adequadas para orientar a cultura de inovação e alcance de objetivos em conjunto.

Neste cenário, é importante imaginar o futuro e tentar construí-lo. Se a empresa consegue perceber desenvolvimentos rapidamente no ambiente de negócios, pode ter mais tempo para responder a choques positivos e negativos (TEECE; LEIH, 2016). Da mesma forma, uma cultura de renovação contínua mantém as organizações flexíveis e receptivas para lidar com as incertezas.

\section{INCERTEZAS, CRISES E A PANDEMIA DA COVID-19}

Um dos grandes desafios das organizações é lidar com o ambiente externo. Transformações econômicas, crises, incertezas, mudanças tecnológicas, sociais e políticas, fazem com que muitas empresas tenham que se adaptar rapidamente. Não há um consenso sobre a diferentes dimensões da incerteza (SHARMA et al., 2020).

Ela pode ser considerada uma variável que influencia um negócio ou a economia como um todo, ou em nível de ambiguidade, complexidade e risco envolvido em um único problema e tomada de decisão. Sendo este conceito relevante para a situação da Covid-19, tratada nesta seção, já que o seu impacto generalizado e quase instantâneo em diferentes países e mercados dificultou a previsão e o controle de qualquer empresa.

Além das incertezas, crises podem causar mudanças e ameaças aos negócios. As crises desencadeiam mudanças significativas e ameaças à sobrevivência das organizações, o que dificulta a capacidade das organizações de lidar com elas (KEOWN-McMULLAN, 1997). Uma crise tem uma profunda influência sobre pessoas, organizações ou mesmo países.

O ano de 2008 foi caracterizado pelo início de uma crise econômica, que se originou 
nos EUA através do crédito imobiliário, e passou a ser global, comprometendo o desempenho do comércio internacional e das economias avançadas e emergentes. Desde a Segunda Guerra Mundial, esta foi considerada a maior recessão econômica, havendo efeitos devastadores para as empresas (KUCKERTZ et al., 2020).

Em 2020 surgiu a crise da COVID-19, um desastre mundial, com impacto significativamente negativo no desenvolvimento da economia global. Foi no final de 2019 que houve a descoberta da síndrome respiratória aguda grave coronavírus 2 (SARS-CoV-2) e, logo em seguida, surge a pandemia de COVID-19 (WANG et al., 2020).

No Brasil, o primeiro caso confirmado foi relatado em 26 de fevereiro de 2020, sendo este um morador de 61 anos do município de São Paulo, Estado de São Paulo, com histórico de viagens para a região da Lombardia, na Itália, e com sintomas leves. Já no Rio Grande do Sul (RS), de acordo com o boletim da OMS de 14 de março de 2020, nesta data, o estado já possuía mais de 2.000 casos notificados (MORALES et al., 2020).

A situação foi caracterizada como uma pandemia em 11 de março de 2020 pelo diretor-geral da OMS Tedros Adhanom Ghebreyesus (SPINELLI; PELLINO, 2020). Embora a ocorrência de uma pandemia causada por um novo vírus não seja surpreendente para os virologistas, as medidas de controle de infecção como distanciamento social adotadas para retardar a disseminação da COVID-19 exercem pressão sobre a economia (SPURK; STRAUB, 2020).

Esta pandemia representa uma crise que impacta em vários aspectos da vida das pessoas em todo o mundo. A maioria dos países afetados tomou várias medidas, como paralisações, fechamento de empresas e escolas, regulamentação de higiene, distanciamento social e rastreamento de mobilidade como forma de diminuir a distribuição da COVID-19 (SPURK; STRAUB, 2020).

Muitos funcionários passaram a trabalhar de casa (como forma de isolamento social), as demandas por entregas domésticas aumentaram, as taxas de insucesso empresarial cresceram exponencialmente e os modelos de negócios começaram a ser revistos em detrimento dos acontecimentos da pandemia (ABUBAKAR, 2020).

A literatura sobre os efeitos da COVID-19 na economia ainda é limitada, visto que é uma situação recente e até a conclusão deste artigo ainda tentava-se controlar o vírus, sem descoberta de cura. No entanto, o que se sabe, é que diante de situações como esta, é importante que as empresas saibam como agir para sobreviver e garantir a sustentabilidade do negócio.

\section{METODOLOGIA}

Esta pesquisa caracteriza-se como descritiva, qualitativa, através de estudos de caso múltiplos (YIN, 2015) em 10 empresas de micro, pequeno e médio porte, localizadas na região metropolitana de Porto Alegre, no Rio Grande do Sul, onde se concentra 37\% da população e 44\% do Produto Interno Bruto (PIB) do Estado (FEDOZZI; SOARES, 2015). Os estudos sobre capacidades dinâmicas se concentram em empresas de grande porte e, desta forma, este estudo tende a contribuir com a análise em empresas menores, além destas terem uma grande importância na economia brasileira (SOUZA; BRITO; ALVARELI, 2011).

O estudo contemplou empresas caracterizadas como indústria, comércio e serviços, de segmentos variados: desenvolvimento de sistemas de informática; empresa de condicionamento físico; indústria metalúrgica; consultoria contábil; comércio de colchões e estofados; comércio e distribuição de materiais para construção civil; consultoria de recursos humanos e espaço de coworking; comércio de acessórios femininos (moda); empresa de 
comunicação e restaurante de comida orgânica. Optou-se por empresas de diferentes segmentos e portes desta região para verificar os reflexos da pandemia e obter um panorama das estratégias utilizadas para enfrentamento da crise e assim verificar as semelhanças e contrastes na diversidade de segmentos e tipos (comércio, indústria e serviços).

A coleta de dados foi realizada durante o mês de Junho de 2020 e 12 empresas foram convidadas para participar. Destas, 10 aceitaram e 2 não retornaram. 0 estudo baseou-se em dados primários e secundários, sendo os primários coletados por meio de entrevistas semiestruturadas e os dados secundários como web site das empresas, apresentação institucional e redes sociais. As entrevistas foram realizadas com os sócios-proprietários ou gestores com cargos estratégicos. A existência de capacidades dinâmicas está intimamente ligada às decisões sobre como alocar os recursos da organização, tendo o líder uma função importante no desenvolvimento das capacidades dinâmicas (TEECE, 2007). As entrevistas foram realizadas por meio de videoconferência individuais, seguindo um roteiro elaborado com base no referencial teórico. Todas foram gravadas e, posteriormente, transcritas. Observou-se que o tempo de existência das empresas varia de 2 a 38 anos e que o período de atuação dos respondentes nas mesmas é de 1 a 21 anos (Figura 1).

As entrevistas semiestruturadas seguiram um roteiro composto por perguntas abertas, divididas em 5 blocos: perguntas gerais sobre o entrevistado; sobre a empresa/negócio; questões que visem a identificação de oportunidades e ameaças (sensing); outras relacionadas ao aproveitamento (seizing) e; por fim, referentes a reconfiguração (reconfiguring). Os 2 primeiros blocos foram construídos para conhecer o perfil dos entrevistados e da empresa. Os 3 últimos blocos tiveram a intenção de vincular as respostas com os microfundamentos que sustentam as capacidades dinâmicas, proposto por Teece (2007).

Figura 1 - Perfil das empresas participantes e respondentes

\begin{tabular}{|c|c|c|c|c|c|}
\hline Segmento & Porte & $\begin{array}{l}\text { Cargo do } \\
\text { respondente }\end{array}$ & Formação & $\begin{array}{l}\text { Tempo na } \\
\text { empresa } \\
\text { (em anos) }\end{array}$ & $\begin{array}{c}\text { Tempo de } \\
\text { existência da } \\
\text { empresa (em anos) }\end{array}$ \\
\hline $\begin{array}{l}\text { Desenvolvimento de } \\
\text { sistemas de informática }\end{array}$ & Pequena empresa & Sócio-Diretor & Superior completo & 21 & 21 \\
\hline $\begin{array}{l}\text { Empresa de } \\
\text { condicionamento físico }\end{array}$ & Microempresa & Sócio-Proprietário & $\begin{array}{l}\text { Pós-Graduação } \\
\text { Concluída }\end{array}$ & 2 & 2 \\
\hline Indústria metalúrgica & Média empresa & $\begin{array}{c}\text { Gerente Geral de } \\
\text { Produção }\end{array}$ & $\begin{array}{l}\text { Pós-Graduação } \\
\text { Concluída }\end{array}$ & 8 & 25 \\
\hline Consultoria contábil & Pequena empresa & Sócio-Proprietário & $\begin{array}{c}\text { Pós-Graduação } \\
\text { Concluída }\end{array}$ & 10 & 32 \\
\hline $\begin{array}{l}\text { Comércio de colchões e } \\
\text { Estofados }\end{array}$ & Microempresa & Sócio-Proprietário & Superior completo & 13 & 38 \\
\hline $\begin{array}{l}\text { Comércio de materiais } \\
\text { para construção civil }\end{array}$ & Pequena empresa & Gerente de Operações & Superior incompleto & 12 & 16 \\
\hline $\begin{array}{l}\text { Consultoria de Recursos } \\
\text { Humanos e espaço de } \\
\text { coworking }\end{array}$ & Microempresa & Proprietário & $\begin{array}{c}\text { Pós-Graduação } \\
\text { concluída }\end{array}$ & 6 & $\begin{array}{c}6 \text { (consultoria de } \\
\mathrm{RH} \text { ) e } 2 \text { (coworking) }\end{array}$ \\
\hline $\begin{array}{l}\text { Comércio de acessórios } \\
\text { Femininos }\end{array}$ & Pequena empresa & Proprietário / Diretor & $\begin{array}{c}\text { Pós-Graduação } \\
\text { concluída }\end{array}$ & 14 & 14 \\
\hline $\begin{array}{l}\text { Empresa de } \\
\text { comunicação }\end{array}$ & Microempresa & Sócio-Proprietário & $\begin{array}{l}\text { Superior completo e } \\
\text { Pós- Graduação } \\
\text { concluída ( } 2 \text { sócias } \\
\text { entrevistadas } \\
\text { simultaneamente) }\end{array}$ & 4 & 4 \\
\hline $\begin{array}{l}\text { Restaurante de comida } \\
\text { orgânica }\end{array}$ & Microempresa & Sócio-Proprietário & Superior incompleto & 1 & 3 \\
\hline
\end{tabular}

Fonte: elaborada pelas autoras (2020).

Os dados coletados por meio das entrevistas e documentos foram analisados por meio da análise de conteúdo qualitativa, seguindo as etapas propostas por Bardin (2016): préanálise, exploração do material e tratamento e interpretação dos resultados. Na pré-análise, ocorre o primeiro contato com os documentos, neste caso a transcrição das entrevistas e 
dados secundários como web site das empresa, documentos de apresentação institucional e redes sociais.

Em seguida, há a exploração e organização do material. Todas as respostas foram tabuladas e categorizadas no software Excel, de acordo com o objetivo das perguntas: informações gerais sobre o entrevistado, gerais sobre a empresa, sensing, seizing e reconfiguring. No bloco de informações gerais sobre o entrevistado foram incluídas as respostas como cargo e tempo de empresa. Já o de informações gerais sobre a empresa, considerou-se o ramo da empresa, quantidade de funcionários, tempo no mercado, como é realizado o planejamento estratégico, sua periodicidade, quem realiza, se é formalizado ou não e quais são suas vantagens competitivas.

No bloco sensing, foram incluídas as respostas como: maneira de identificação de necessidades dos clientes, novas oportunidades e concorrência; oportunidades e ameaças observadas durante a pandemia para o negócio. No bloco seizing, considerou-se as respostas referentes às ações realizadas durante a pandemia. Por fim, no bloco reconfiguring, foram apontadas as consequências observadas após implementação de ações durante a pandemia, ações e estratégias que estão sendo planejadas diante do ocorrido. Referente à etapa de tratamento e interpretação de resultados, procurou-se tornar os dados significativos e válidos, relacionando-os com a fundamentação teórica. Nesta etapa, deve-se buscar o que se esconde sob a aparente realidade, o que significa verdadeiramente o discurso enunciado, o que querem dizer, em profundidade, certas afirmações, aparentemente superficiais (CÂMARA, 2013).

\section{ANÁLISE DOS RESULTADOS}

Para entender o contexto das empresas com relação às suas estratégias, foi questionado se elas têm estratégias definidas e como são planejadas. Os entrevistados afirmaram possuir definições estratégicas tanto de modo formal, quanto informais. Há controvérsias entre os autores sobre a realização de planejamento estratégico em pequenas e médias empresas (LIMA, 2010). Quando este é considerado uma atividade que exige formalidade e racionalidade, os estudos concluem que é incompatível com a condição destas empresas, que exige agilidade na tomada de decisão. Por outro lado, quando se entende este processo como algo flexível, informal, não sistemático e/ou que admite a intuição dos gestores, torna-se mais compatível com a condição de pequenas e médias empresas.

A periodicidade das estratégias foi bianual, anual e semestral. Os entrevistados relataram que mesmo sendo anual ou bianual há necessidade de revisar e acompanhar mensalmente ou semanalmente. Cabe destacar, que aqueles que relataram ter planejamento formalizado, apontam dificuldades de segui-lo, devido às necessidades de mudanças constantes. Alguns, também, justificaram a dificuldade pelo fato de ser empresas familiares. Em comparação com empresas de grande porte, as pequenas e médias se diferenciam por serem mais informais na formulação de estratégias e por ter este processo representado, geralmente, pelo proprietário ou alta gestão da empresa (DALLA; GONÇALVES; MUNIZ, 2009). Há estatísticas onde a periodicidade de definição de estratégias em pequenas e médias empresas é menor, do que as de grande porte, havendo maior necessidade de flexibilidade nestas definições (KRAUS; HARMS; SCHWARZ, 2008).

Os indicadores analisados para o desenvolvimento de estratégias são diversos. Há quatro processos de planejamento que se diferenciam pelo nível de sofisticação (BRACKER; PEARSON, 1986). O planejamento estratégico estruturado contempla a análise do ambiente e determinação das forças e fraquezas, de maneira formalizada. O operacional estruturado 
inclui controle de produção, custos e pessoal, sendo também formalizado. Já o intuitivo é informal e implementado com base na intuição e experiência do proprietário. $E$ o desestruturado significa que não é mensurável e é informal.

Nas empresas estudadas, identificaram-se características destes quatro tipos de planejamento. Por exemplo, para a empresa de desenvolvimento de software, são analisados os encerramentos ou início de contratos com clientes e, a partir disso, os motivos de entrada e saída, necessidades de melhorias e de investimentos. Já para a indústria metalúrgica e para o comércio de acessórios femininos são consideradas as tendências de moda, visto que as tendências indicam as necessidades de mercado. Além disso, essas realizam a observação de concorrentes, com relação à produtos, preços, entre outros.

A empresa de comunicação define sua estratégia com base em três pilares: comercial, marketing e pessoas. Assim, com base no período anterior e nas novas necessidades, definem valores para investimentos em anúncios para captação de clientes, ações de prospecção e necessidades de desenvolvimento e melhorias relacionadas à equipe de trabalho. A consultoria de $\mathrm{RH}$ e espaço de coworking observam as ações de concorrentes e de mercado e seus resultados do último ano.

A empresa de condicionamento físico disse que está neste momento colocando em prática os objetivos de sua estratégia de negócios que é a venda de franquias. Para isto, conta com o apoio de uma consultoria que oferece suporte no planejamento estratégico. Já a consultoria contábil relatou ter definição de estratégias formalizadas, mas enfatiza a rapidez de mudanças no mercado e na legislação. Por este motivo, considera importante a realização de reuniões semanais para acompanhamento do planejamento. Em seu web site, verificou-se a divulgação de seu negócio, visão, missão e princípios.

O comércio e distribuição de materiais para construção civil possui planejamento formal em longo prazo, mas revisa em menor periodicidade os seguintes aspectos: verba orçamentária, necessidades de investimentos, clientes prioritários, formas de contato com o cliente, indicadores financeiros, atividades e processos da empresa, bem como desempenho de funcionários. Pode-se observar em seu web site a divulgação de sua missão, visão e valores.

O proprietário do restaurante de comida orgânica relata que planejou algumas ações para a empresa logo que adquiriu o empreendimento, há menos de um ano. Porém com a pandemia e restrições de isolamento, tiveram que repensar. Para isto, fecharam a empresa por dois meses para se reorganizar, considerando outras maneiras de atendimento, diminuição do público, desperdício de alimentos e necessidades de distanciamento físico.

A partir dos dados apresentados pode-se constatar que a realização do planejamento estratégico é geralmente feita pelos sócios-proprietários ou gerentes da empresa. Em alguns casos, há o apoio de consultoria especializada. Quando questionados com relação à vantagem competitiva da empresa, oito itens foram citados, sendo eles: diversidade de tecnologias; conhecimento técnico; prazo de entrega; qualidade do produto; histórico e estabilidade da empresa; estoque para pronta entrega; variedade de produtos e atendimento.

Algumas empresas citaram mais de uma vantagem competitiva. $O$ atendimento foi o mais enfatizado pelos entrevistados, com destaque para o tratamento individualizado com clientes, proximidade nas relações, confiança, atendimento técnico especializado, empatia e valores humanos. Em relação à análise da estratégia e criação de vantagem competitiva no mercado empresarial, em um primeiro momento, havia a necessidade de compreensão dos ativos e saber quais condições os transformariam em vantagem competitiva sustentável. No entanto, a necessidade foi direcionada para os processos dinâmicos de geração, desenvolvimento e acumulação ativos, sendo as capacidades dinâmicas os fatores-chave para 
a estratégia da empresa (LÓPEZ, 2005).

\subsection{CAPACIDADE DE IDENTIFICAÇÃO (SENSING)}

Na presente pesquisa, verificou-se que a maioria das empresas participantes conta com a observação informal do mercado e capacidade cognitiva dos sócio-proprietários ou gerentes, para identificação de oportunidades. A capacidade cognitiva gerencial é a capacidade de um gerente individual executar atividades mentais que compreendem a cognição, sendo possível desenvolvê-la com a prática e treinamento de atividades mentais (HELFAT; PETERAF, 2015).

Sendo assim, as capacidades cognitivas podem ser diferentes entre os gestores, conforme suas práticas. O estímulo ao empreendedorismo é importante para o desenvolvimento de capacidades dinâmicas e identificação de oportunidades (MAHRINGER; RENZL, 2018).

Entre os entrevistados, outras formas de identificação de oportunidades foram citadas, como: pesquisas de satisfação de clientes, "cliente oculto", participação de associações no ramo da empresa que permite contato com concorrentes, controle diário com os motivos de vendas não concluídas, proximidade entre vendedores e clientes, relações com fornecedores, participação em feiras e eventos, auxílio de serviços de consultoria, acompanhamento de notícias em veículos de comunicação. Todos os entrevistados citaram a importância de acompanhar as necessidades do mercado e pensar em novas formas de atendê-los diante da crise econômica gerada pela pandemia da COVID-19. O Quadro 1 apresenta o resumo das práticas indicadas pelas empresas.

Quadro 1 - Sensing

\begin{tabular}{|c|c|c|}
\hline \multicolumn{3}{|c|}{ SENSING } \\
\hline $\begin{array}{c}\text { Práticas para identificação de } \\
\text { oportunidades e ameaças }\end{array}$ & Ameaças & Oportunidades \\
\hline Observação informal do mercado & $\begin{array}{l}\text { Empresas clientes fecharam } \\
\text { ou reduziram custos }\end{array}$ & $\begin{array}{l}\text { Migração do público consumidor } \\
\text { para determinados mercados }\end{array}$ \\
\hline Capacidade cognitiva gerencial & Desemprego & $\begin{array}{l}\text { Necessidade de maior investimento } \\
\text { em marketing (específico para } \\
\text { empresas do ramo) }\end{array}$ \\
\hline $\begin{array}{l}\text { Visitas em clientes para diagnósticos de } \\
\text { necessidades }\end{array}$ & $\begin{array}{l}\text { Menor poder de aquisição do } \\
\text { consumidor }\end{array}$ & $\begin{array}{l}\text { Desenvolvimento de novos } \\
\text { produtos ou serviços, atendendo um } \\
\text { novo nicho do mercado }\end{array}$ \\
\hline $\begin{array}{l}\text { Monitoramento do surgimento de novas } \\
\text { tecnologias para poder sugerir } \\
\text { aos clientes }\end{array}$ & Clima de tensão e incerteza & $\begin{array}{l}\text { Aumento do consumo através do } \\
\text { e-commerce }\end{array}$ \\
\hline Pesquisas com clientes & $\begin{array}{l}\text { Possibilidade de contágio do } \\
\text { vírus da COVID-19 }\end{array}$ & $\begin{array}{l}\text { Necessidade de produtos ou } \\
\text { serviços que impactem em redução } \\
\text { de custos }\end{array}$ \\
\hline $\begin{array}{l}\text { Observação in loco nos clientes e } \\
\text { relacionamento com os mesmos }\end{array}$ & $\begin{array}{l}\text { Impossibilidade de } \\
\text { atendimentos presenciais }\end{array}$ & $\begin{array}{l}\text { Maior proximidade com clientes e } \\
\text { flexibilização entre empresa e } \\
\text { parceiros }\end{array}$ \\
\hline $\begin{array}{l}\text { Acompanhamento de notícias sobre o } \\
\text { mercado em veículos de comunicação }\end{array}$ & & \\
\hline Participação de associações na área & & \\
\hline Participação em feiras e eventos & & \\
\hline $\begin{array}{l}\text { Participação em cursos de } \\
\text { aperfeiçoamento }\end{array}$ & & \\
\hline
\end{tabular}

Fonte: elaborado pelas autoras (2020). 
Os entrevistados foram questionados sobre quais foram as oportunidades e ameaças identificadas diante da pandemia. Algumas empresas comentaram que observaram mais ameaças do que oportunidades, sendo estas dos seguintes segmentos: indústria metalúrgica, consultoria de recursos humanos e coworking, comércio de acessórios femininos, restaurante de comida orgânica. Estas, até o momento têm conseguido se adaptar, havendo preocupação sobre a condução dos negócios diante de incertezas. No entanto, todos entrevistados relataram que foram incentivados pela situação da pandemia a repensar processos e estratégias. Empresas têm maior probabilidade de adaptar seu modelo de negócios diante de ameaças percebidas do que em condições de oportunidades (SAEB; LIEN; FOSS, 2017). Quanto às ameaças, foram citadas: empresas clientes que fecharam ou reduziram custos impactando na redução do seu faturamento; aumento do desemprego; menor poder de aquisição do consumidor; clima de tensão e incertezas; possibilidade de contágio do vírus entre a equipe e necessidade da empresa não poder atender de forma presencial devido aos decretos legais.

Com relação às oportunidades, os entrevistados relataram alguns exemplos. A empresa de condicionamento físico disse que clientes que frequentavam espaços com aglomeração de pessoas para realização de atividade física, passaram a buscar a prática de exercícios físicos de forma individualizada, ocorrendo uma migração, já que eles atendem até duas pessoas por vez. Além disto, é uma possibilidade para as pessoas conhecerem as tecnologias que oferecem melhores resultados em menor tempo, comparando com as academias. Também observaram que a expansão através de franquias é uma oportunidade diante da crise, pois o investimento é baixo e percebem diversos profissionais do ramo de educação física desempregados ou com carga horária reduzida buscando investir em novos negócios. Em uma crise, é necessário encontrar oportunidades e traçar um futuro melhor, não apenas fazer com que a empresa sobreviva (VARGO; SEVILLE, 2011).

A empresa de comunicação observou uma maior busca por serviços de marketing e publicidade. Identificou um novo público: profissionais que, em função da pandemia, tiveram sua carga horária reduzida nos empregos atuais ou que ficaram desempregados, havendo disposição para empreender. Assim, estas pessoas passaram a investir em seu marketing pessoal e profissional. Esta mesma empresa acredita que a crise a impulsionou para a busca de novas oportunidades, projetos e clientes, o que contribuiu para o seu aumento de faturamento. Embora muitas empresas ajam de maneira conservadora diante de um ambiente de crise, aquelas que se direcionam para mudanças tendem a se beneficiar com as oportunidades criadas (WAN; YIU, 2009).

As empresas do segmento de desenvolvimento de software e consultoria contábil detectaram maior procura de clientes interessados em produtos ou serviços que contribuam para redução de custos. A indústria metalúrgica identificou uma oportunidade de produzir novos produtos (clipe nasal) e assim atender clientes de segmentos diferentes, não se concentrando apenas em indústrias calçadistas e segmentos de vestuários (percebem que estes ramos foram mais afetados). O entrevistado acredita que a crise fez com que percebessem que tinham capacidade para produzir outros produtos.

O sócio-proprietário do comércio de colchões e estofados observou o aumento do faturamento com a implantação do e-commerce, que não possuíam antes da pandemia. $\mathrm{A}$ empresa de comunicação e a consultoria de $\mathrm{RH}$ e coworking apontam que a crise fez com que eles se aproximassem mais dos clientes, mantendo contato mais próximo e estabelecendo relação de parceria. Além disso, perceberam a flexibilização e negociação como algo positivo. Em situações de crise, há maior necessidade de flexibilidade. Para isto, é importante pensar no futuro com robustez e delegar autoridade, antecipar cenários, ser criativo, ter agilidade na 
tomada de decisão, ser resiliente e aproveitar os ativos minimizando os danos (EVANS; BAHRAMI, 2020).

Para o comércio e distribuição de materiais para construção civil, a crise os obrigou a verificar o que é essencial para o negócio, reduzindo desperdícios. Alguns entrevistados não conseguiram identificar impactos positivos, trazendo em suas falas o quanto estão com dificuldades nos negócios. A consultoria contábil e a empresa do ramo de construção civil observaram oportunidades de negócio, que estão sendo analisadas, não sendo possível informar mais detalhes.

\subsection{CAPACIDADE DE APROVEITAMENTO (SEIZING)}

A partir do momento que uma oportunidade é detectada, ela deve ser aproveitada através de novos produtos, processos ou serviços (TEECE, 2007). Para isso, são necessárias decisões de investimentos, bem como realizá-las no tempo certo. Dessa forma, nesta pesquisa, foi investigado quais foram as ações realizadas pelas empresas devido à crise da COVID-19. O Quadro 2 apresenta o resumo destas práticas.

Quadro 2 - Seizing

\begin{tabular}{|l|}
\hline \multicolumn{1}{|c|}{ Seizing } \\
\hline Medidas preventivas de cuidados relacionados à saúde e segurança de funcionários. \\
\hline Reuniões e contatos com clientes de forma online e implantação do trabalho remoto. \\
\hline $\begin{array}{l}\text { Para redução de custos, diminuição do quadro de funcionários, suspensões de contratos, redução de carga } \\
\text { horária e férias. Além de negociações com fornecedores. }\end{array}$ \\
\hline Para captação de novos clientes, maior investimento em ações de marketing e em vendas online. \\
\hline Desenvolvimento de novos produtos e/ou serviços, atendendo novos tipos de clientes. \\
\hline Aumento do estoque de produtos para entregas imediatas. \\
\hline Estabelecimento de relações de parcerias e alianças estratégicas \\
\hline
\end{tabular}

Fonte: elaborado pelas autoras (2020).

Percebe-se preocupação por parte dos entrevistados com relação à saúde e segurança de seus funcionários, em razão das possibilidades de contágio com o vírus, seguindo as orientações dos decretos do governo. Em todos os casos foram tomadas medidas relacionadas à higiene e proteção, como o uso de máscaras, álcool gel e distanciamento físico (em alguns casos foi necessário reestruturação de layout). Vários órgãos como a OMS emitiram pareceres com orientações para prevenção de propagação do vírus (SOHRABI et al., 2020).

Para redução de custos, os entrevistados relataram necessidade de diminuição do quadro de funcionários, bem como suspensões de contratos de trabalho e reduções de carga horária. Devido à necessidade de isolamento e distanciamento físico, empresas como a indústria metalúrgica, o comércio de acessórios femininos e a consultoria contábil concederam férias. Com clientes, reuniões e demais necessidades de contatos passaram a serem priorizadas em formato online. $\mathrm{O}$ aumento de investimentos em ações de marketing e comercial são ações realizadas, citadas pelo comércio de colchões e estofados, consultoria de $\mathrm{RH}$ e coworking, comércio de acessórios femininos, empresa de comunicação e restaurante de comida orgânica.

Quanto às oportunidades de negócios, a indústria metalúrgica passou a fabricar outros produtos atendendo clientes de ramos diferentes, já que o setor calçadista e vestuário, principais nichos que atendia, foram bastante afetados com a crise. O restaurante investiu em vendas de produtos alimentícios que possam ser comercializados em mercados e mudaram o formato de servir os alimentos. Além disso, alteraram os dias de atendimento, passando a atender aos domingos, pois observaram poucas opções na cidade neste dia.

A empresa de comunicação passou a oferecer combos de produtos com preços 
menores para atingir uma quantidade maior de clientes. Também iniciou a venda de um produto novo voltado para profissionais que estavam em busca de empreender e melhorar sua imagem. A governança dos segmentos de clientes, a lealdade, a oferta de produtos, os canais de distribuição, vendas e comunicação e o gerenciamento da marca e da reputação de uma empresa, são microfundamentos relevantes da função de marketing e vendas (HAAPANEN et al., 2019).

O comércio de colchões e estofados, o comércio de acessórios femininos e o restaurante de comida orgânica implantaram vendas online, aperfeiçoando ou criando site de vendas, utilizando redes sociais e plataformas de mensagens instantâneas. Os entrevistados alegaram que, devido ao seu porte, o gerenciamento destes canais de vendas e atendimento online, acaba sendo realizado pelo proprietário ou gerente. Alguns estudos já dizem que a digitalização, ou seja, o uso de tecnologias digitais, tem o potencial de ajudar positivamente as pequenas e médias empresas a responderem a crises, como a crise da COVID-19. Empresas digitalizadas podem alavancar suas capacidades dinâmicas para detectar crises, aproveitar oportunidades e recursos para lidar com a crise (GUO et al., 2020). Além disso, alguns decidiram investir em estoque com maior quantidade para entrega imediata, para aproveitar as oportunidades de vendas e porque alguns fornecedores precisaram suspender os atendimentos como medida de isolamento.

A atuação com parceiros em forma de colaboração e compartilhamento de conhecimento foram citados pela empresa de comunicação e pelo comércio de acessórios femininos. Esta última fala sobre a realização de uma ação para incentivo ao comércio local contribuindo para uma instituição beneficente. A outra diz que conta com parceiros que dispõem de conhecimento técnico em determinada área no portfólio de seus serviços, como uma aliança estratégica. As alianças estratégicas podem ser determinantes para criar valor no desenvolvimento de capacidades dinâmicas (FERNANDES; FERREIRA; FLEURY, 2019).

\subsection{CAPACIDADE DE RECONFIGURAÇÃO (RECONFIGURING)}

A reconfiguração é necessária para manter a evolução da empresa e tentar escapar das dependências desfavoráveis (TEECE, 2007). Assim, o sucesso cria um nível de rotinas que é necessário para a eficiência operacional. Ou seja, é necessária uma orquestração periódica dos ativos, o que pode envolver o redesenho do modelo de negócios, atividades de realinhamento de ativos e a reformulação de rotinas.

Dos entrevistados, a empresa de comunicação e a de condicionamento físico enfatizaram que dão autonomia à equipe e contam com suas ideias e sugestões para a tomada de decisões. Todas as demais disseram possuir uma gestão centralizadora. A descentralização contribui para a reconfiguração das capacidades dinâmicas, uma vez que se pode contar com ideias e percepções diferentes e em ambientes de ritmos acelerados é importante ter autonomia para tomadas de decisões (TEECE, 2007). Geralmente nas pequenas e médias empresas, o proprietário não delega poder e responsabilidades à equipe (SINGH; GARG; DESHMUKH, 2008). Sendo assim, percebe-se a importância do papel dos gestores nas empresas participantes da pesquisa, uma vez que as estratégias e decisões acabam sendo realizadas por eles, em maioria.

As empresas participantes da pesquisa informaram como pensam em agir em relação às estratégias após a pandemia da COVID-19, conforme o Quadro 3. Quanto aos funcionários, todos relataram que pretendem manter mais cuidados relacionados à saúde, em comparação de como era antes da pandemia. A empresa de condicionamento físico enfatizou a estratégia 
de investir em materiais de alta qualidade voltados para a saúde da equipe, o que contribui para um clima de maior confiança e boas relações. Nesse sentido, o estabelecimento de um clima de confiança incentiva o comportamento voltado para mudanças (FAINSHMIDT; FRAZIER, 2017). A empresa de comunicação falou que pretende ter maior flexibilidade quanto ao trabalho home office trazendo mais liberdade à equipe para quando quiserem atuar de forma remota, já que percebeu resultados positivos com a experiência.

Quadro 3-Reconfiguring

\section{Reconfiguring}

Mais cuidados com a saúde dos funcionários; retomada das atividades presenciais, conforme possível (em maioria).

Manter as estratégias de novos produtos / serviços desenvolvidos na pandemia, atendendo novos mercados.

Manter atenções voltadas ao comércio e marketing digital, sendo necessário aperfeiçoamento através de treinamentos nesta área.

Manter aproximação e contatos mais frequentes com clientes.

Fonte: elaborado pelas autoras (2020).

Para a empresa de desenvolvimento de software, as atividades remotas seriam uma opção, para evitar investimentos caso a empresa precise expandir sua estrutura física no futuro. As demais pensam em retomar as atividades ao presencial, por oferecer melhores condições e conforto aos funcionários. No caso do restaurante de comida orgânica, da empresa de condicionamento físico, do comércio de acessórios femininos, do comércio de colchões e estofados os entrevistados relataram que a entrega do produto ou serviço depende de contato físico ou contribui para ampliar os resultados financeiros.

Aqueles que implementaram estratégias voltadas a novos produtos ou serviços ou formas diferentes de contato com os clientes, têm a intenção de mantê-los. Por exemplo, a empresa de condicionamento físico está em processo de expansão, através de franquias, e assim continuará, conforme sua estratégia. Para a manutenção das franquias, o entrevistado afirmou que serão necessários processos padronizados e treinamentos frequentes. A reconfiguração inclui o gerenciamento de conhecimento, a reconfiguração com base em recursos e a co-especialização de ativos (FERNANDES; FERREIRA; FLEURY, 2011).

Empresas como a indústria metalúrgica e a de comunicação, pretendem manter a venda dos novos produtos e dos que já eram comercializados, atingindo outros mercados e ampliando as possibilidades de negócios. Acreditam que estes processos já estão adaptados à estrutura da empresa, não havendo necessidades de alterações nestes processos. Dentro da empresa, o antigo e o novo devem se complementar, mantendo e ajustando a complementaridade de ofertas, rotinas e estruturas de produtos (TEECE, 2007). A empresa de $\mathrm{TI}$ comentou que percebe a necessidade de atingir clientes de outros ramos, visto que sua receita é concentrada em $60 \%$ num único tipo de cliente.

Verifica-se um foco para ações concentradas em comércio e marketing digital. Há comentários de investimentos em vendas online e/ou em mídias sociais na maioria das empresas, exceto nos segmentos: desenvolvimento de software, indústria metalúrgica, consultoria contábil e comércio de materiais de construção civil. As empresas identificaram resultados positivos com estas ações e por isto pretendem seguir investindo.

Como forma de aperfeiçoamento, comentam a necessidade de treinamentos para as equipes voltados ao atendimento online e possível necessidade de reestruturação de processos internos. Além destas ações, a empresa de comunicação e a de condicionamento físico relataram maior aproximação com os clientes, através de contatos mais frequentes, como forma de retê-los e entender suas necessidades. Acreditam que esta é uma necessidade atual, que deve ser mantida após a pandemia. 
A partir dos dados, verifica-se que os entrevistados relataram preocupações e que se sentem inseguros sobre como agir, considerando as incertezas geradas pela crise da COVID19. Algumas empresas, em suas falas, não percebem tanto impacto negativo da crise em comparação com os outros, devido ao tipo de produto ou serviço vendido, como por exemplo, o comércio de materiais para construção civil e a empresa de comunicação. Esta última possivelmente tenha sofrido menos devido a necessidade do mercado de maiores investimentos em marketing para aumento da receita, em comparação com outras. A outra talvez por ser considerada uma atividade essencial. A empresa de consultoria de $\mathrm{RH}$ e coworking apontou maior dificuldade de identificar oportunidades diante da crise e visualizar alternativas para lidar com o momento.

As empresas deste estudo citam como exemplo o relacionamento e a proximidade com clientes para identificação de oportunidades. Esta relação próxima acaba sendo uma vantagem devido sua estrutura e menor porte (MORALES-RUBIANO et al., 2016). Outra maneira de desenvolver capacidades dinâmicas para lidar com ambientes voláteis, é através da gestão do conhecimento e incentivo ao aprendizado. Alguns entrevistados, conforme apontado na etapa de sensing, buscam conhecimentos através de cursos de aperfeiçoamento e participação em feiras. As empresas devem adotar o aprendizado para desenvolver capacidades dinâmicas ao longo do tempo (HERMAWATI, 2020). Ainda ser capazes de converter em conhecimento as informações obtidas e, posteriormente, aplicá-las a sistemas, processos ou técnicas de produção.

Em relação ao microfundamento seizing, observa-se que as empresas como a indústria metalúrgica e a de comunicação, desenvolveram novos produtos para serem comercializados. Desse modo, possuem uma orientação proativa para o mercado, ou seja, identificam as necessidades não apenas dos consumidores, mas do mercado como um todo. Assim, oferecem soluções por meio da inovação de produtos e serviços. São exemplos de situações que comprovam, que mesmo com menos recursos (devido ao seu porte) em comparação com empresas multinacionais e de grande porte, é possível fornecer soluções proativamente para mercados turbulentos e trazer insights importantes que consequentemente podem gerar inovação (CANTALEANO; RODRIGUES; MARTINS, 2018).

Das entrevistadas, três comentaram ser empresas familiares (consultoria contábil, comércio de colchões e estofados e comércio de materiais para construção civil) e que, por este motivo, percebem mais dificuldades em implementar mudanças. A literatura aponta que neste tipo de empresa, há uma tendência em investir em inovação de forma menos intensiva, possivelmente devido ao conservadorismo e aversão ao risco entre muitas empresas familiares (BOGODISTOV et al., 2017). A aversão ao risco e o conservadorismo podem restringir a capacidade das empresas familiares de perceber e moldar novas oportunidades, impactando negativamente no desenvolvimento de capacidades dinâmicas. Quanto ao microfundamento reconfiguring, o incentivo a novos projetos, novas ideias, gestão do conhecimento e decisões descentralizadas são práticas que poderiam ser utilizadas pelas empresas entrevistadas, visto que não foram citadas nas entrevistas.

Sendo assim, percebe-se que todos os entrevistados identificaram as mudanças de mercado e sentem as incertezas do ambiente, precisando se adaptar e reinventar seus negócios. Estudos dizem que em ambientes altamente incertos, com necessidade de aumentar a flexibilidade estratégica da empresa, é necessário se envolver em atividades de previsão estratégica, melhorando a qualidade das discussões e tomada de decisão (HAARHAUS; LIENING, 2020). Estes mesmos autores desenvolveram em seu trabalho um instrumento para avaliar a condição atual das capacidades de previsão de suas respectivas 
organizações. Esta ferramenta poderia ser utilizada pelas empresas da presente pesquisa, podendo aprimorar suas atividades de previsão e fortalecer as capacidades dinâmicas. Dessa forma, percebe-se que as empresas estudadas realizam práticas de identificação e aproveitamento de oportunidades, havendo necessidade de desenvolver o microfundamento de reconfiguração.

\section{CONSIDERAÇÕES FINAIS}

Diante da pandemia da COVID-19, a população foi orientada com medidas restritivas de isolamento e voltadas à saúde e segurança, para evitar a propagação do vírus. Esta situação gerou consequências para os negócios, havendo necessidade de adaptação tanto com relação aos funcionários, fornecedores e clientes.

Sendo assim, este estudo buscou identificar as estratégias de enfrentamento da crise diante da pandemia da COVID-19 sob a lente das capacidades dinâmicas. Percebeu-se que todas as empresas participantes da pesquisa, mesmo realizando ações para detecção de oportunidades (sensing) antes da crise, relataram que não estavam preparadas para este tipo de situação e mostraram-se receosas diante das incertezas de mercado e não descoberta da cura para o vírus. Para identificação de oportunidades, foram citados vários exemplos como: participação em cursos, feiras e eventos, realização de pesquisas e relações com clientes e fornecedores, entre outros. Em alguns casos, os entrevistados comentaram que a pandemia contribuiu para que realizassem medidas para evitar desperdícios e buscar novas oportunidades.

Quanto à capacidade de aproveitamento (seizing), todas as empresas disseram que realizaram ações para adaptação diante da COVID-19, sendo a maioria focada na equipe conforme orientações da Organização Mundial da Saúde. A indústria metalúrgica e a empresa de comunicação realizaram o desenvolvimento de novos produtos ou serviços. Alguns também implantaram melhorias em processos relacionadas à comercialização e marketing de produtos e serviços, além de maior investimento em e-commerce, como no comércio de colchões e estofados, consultoria de RH e coworking, comércio de acessórios femininos, empresa de comunicação e restaurante de comida orgânica.

Já a capacidade de reconfiguração (reconfiguring), percebe-se que é a que mais precisa atenção por parte dos entrevistados, pois estes se sentem inseguros quanto às incertezas de mercado diante da propagação do vírus. Para isto, sugere-se aumentar a participação dos funcionários na tomada de decisões, contar com parcerias para formação de estratégias, incentivar o empreendedorismo interno e a gestão do conhecimento.

Pode-se destacar como limitações do estudo a realização da pesquisa com amostra de dez empresas nesta região, não sendo possível generalizar para outras realidades. Sendo assim, como sugestão de estudos futuros, pode-se realizar a mesma pesquisa aplicando outras variáveis, como regiões diferentes e outros segmentos. Também, sugere-se realizar um novo estudo após a pandemia, relacionando as estratégias realizadas com o desempenho destas empresas.

Sendo assim, as capacidades dinâmicas tendem a contribuir para as estratégias de enfrentamento da crise diante da pandemia da COVID-19. As empresas que têm capacidade de detectar as oportunidades e ameaças podem ter mais tempo para responder às incertezas do ambiente. Da mesma forma, empresas que aprendem a reconfigurar, podem ser mais resilientes quando o ambiente de incerteza exigir transformações. Esta pesquisa contribui no âmbito acadêmico, já que a pandemia da COVID-19 é uma situação recente e há poucos estudos que relacionam este tema com capacidades dinâmicas. No âmbito gerencial, a 
Capacidades dinâmicas e estratégias para enfrentamento da crise diante da pandemia da COVID-19

pesquisa fornece insights para as empresas sobre estratégias diante das incertezas de mercado.

\section{REFERÊNCIAS}

ABUBAKAR, A. Coronavirus (COVID-19): Effect and Survival Strategy for Businesses. Journal of Economics and Business, Netherlands, v. 3, n. 2, p. 661-671, 2020. DOI:

https://doi.org/10.31014/aior.1992.03.02.229.

AGUIAR, S. S.; FROEHLICH, C.; ZANANDREA, G.; NODARI, C. H.; SCHMIDT, S. Contribuição das capacidades dinâmicas para a inovação sob a lente dos microfundamentos. Revista Gestão Organizacional (RGO), Santa Catarina, v. 13, n. 3, set./dez., 2020. DOI:

https://doi.org/10.22277/rgo.v13i3.5106.

BARDIN, L. Análise de conteúdo. São Paulo: Edições, 2016.

BARNEY, J. Firm Resources and Sustained Competitive Advantage. Journal of Management, United States, v. 17, n. 1, p. 99-120, 1991. DOI: https://doi.org/10.1016/S0742-

3322(00)17018-4.

BARRETO, I. Dynamic Capabilities: A review of past research and an agenda for the future. Journal of Management, United States, 2010. DOI:

https://doi.org/10.1177/0149206309350776.

BOGODISTOV, Y.; PRESSE, A.; KRUPSKYI, O. P.; SARDAK, S. Capacidades dinâmicas de gênero em micro empresas. RAE, São Paulo, v. 57, n. 3, p. 273-282, maio/jun., 2017. DOI: https://doi.org/10.1590/S0034-759020170308.

BRACKER, J. Y.; PEARSON, J. N. Planning and financial performance of small, mature firms. Strategic Management Journal, Chicago, v. 7, n. 6, p. 503-522, nov./dez., 1986. DOI: https://doi.org/10.1002/SMJ.4250070603.

CÂMARA, R. H. Análise de conteúdo: da teoria à prática em pesquisas sociais aplicadas às organizações. Gerais: Revista Interinstitucional de Psicologia, Minas Gerais, v. 6, n. 2, p. 179-191, 2013.

CANTALEANO, K. R.; RODRIGUES, G. P.; MARTINS, T. S. The mediating effect of proactive market orientation capability in entrepreneurial orientation and service innovation. RAM.

Revista de Administração Mackenzie, São Paulo, v. 19, n. 1, 2018. DOI: https://doi.org/10.1590/1678-6971/eramr180038.

CHIRICO, F.; SIRMON, D. G.; SCIASCIA, S.; MAZZOLA, P. Resource orchestration in family firms: Investigating how entrepreneurial orientation, generational involvement, and participative strategy affect performance. Strategic Entrepreneurship Journal, Chichester, v. 5, n. 4, p. 307-326, 2011. DOI: https://doi.org/10.1002/sej.121.

COLLIS, D. J. Research note: how valuable are organizational capabilities? Strategic 
Management Journal, Chicago, v. 15, n. 1, p. 143-152, 1994. DOI: https://doi.org/10.1002/smj.4250150910.

DALLA, W. D.; GONÇALVES, C. A.; MUNIZ, R. M. O pensamento do estrategista: fatores que asseguram a tomada de decisões estratégicas nas pequenas e médias empresas. Revista Ibero-Americana de Estratégia, São Paulo, v. 8, n. 2, jul./dez., 2009. DOI: https://doi.org/10.5585/riae.v8i2.1641.

EISENHARDT, K. M.; MARTIN, J. A. Dynamic capabilities: what are they? Strategic Management Journal, Chicago, v. 21, n. 10-11, p. 1105-1121, 2000. DOI: https://doi.org/10.1002/1097-0266(200010/11)21:10/113.0.CO;2-E.

EVANS, S.; BAHRAMI, H. Super-Flexibility in Practice: Insights from a Crisis. Global Journal of Flexible Systems Management, New Delhi, v. 21, n. 3, p. 207-214, 2020. DOI: https://doi.org/10.1007/s40171-020-00246-6.

FAINSHMIDT, S.; FRAZIER, M. L. What Facilitates Dynamic Capabilities? The Role of Organizational Climate for Trust. Long Range Planning, London, v. 50, n. 5, p. 550-566, 2017. DOI: https://doi.org/10.1016/j.Irp.2016.05.005.

FEDOZZI, L.; SOARES, P. R. R. A Região Metropolitana de Porto Alegre nos (des) caminhos da metropolização brasileira. In: SOARES, P. R. R. (Org.) Porto Alegre: transformações na ordem urbana. v. 1. Rio de Janeiro: Letra Capital, 2015. p. 42-72.

FELIN, T.; FOSS, N. J.; HEIMERIKS, K. H.; MADSEN, T. L. Microfoundations of routines and capabilities: Individuals, processes, and structure. Journal of Management Studies, New Jersey, v. 49, n. 8, p. 1351-1374, 2012. DOI: https://doi.org/10.1111/j.14676486.2012.01052.x.

FERNANDES, K. R.; FLEURY, M. T. L.; DA SILVA, L. F. A Transformação digital e o desenvolvimento de capacidades dinâmicas: um mapeamento da literatura. In: XLIII Encontro da ANPAD, 2019, São Paulo. Anais Eletrônicos [...]. São Paulo: ANPAD, 2019. Disponível em:

https://www.anpad.org.br/eventos.php?cod_evento=1\&cod_edicao_subsecao $=1665 \&$ cod_ evento_edicao=96\&cod_edicao_trabalho=26843. Acesso em: 01 jun. 2019

FRANK, H.; GÜTTEL, W.; KESSLER, A. Environmental dynamism, hostility, and dynamic capabilities in medium-sized enterprises. The International Journal of Entrepreneurship and Innovation, London, v. 18, n. 3, p. 185-194, 2017. DOI: https://doi.org/10.1177/1465750317723219.

GIROD, S. J. G.; WHITTINGTON, R. Reconfiguration, restructuring and firm performance: Dynamic capabilities and environmental dynamism. Strategic Management Journal, Chicago, v. 38, n. 5, p. 1121-1133, 2017. DOI: https://doi.org/10.1002/smj.2543.

GUERRA, R. M. A.; TONDOLO, V. A. G.; CAMARGO, M. E. O que (ainda) podemos aprender sobre capacidades dinâmicas. Revista Ibero Americana de Estratégia, São Paulo, v. 15, n. 1, 
Capacidades dinâmicas e estratégias para enfrentamento da crise diante da pandemia da COVID-19

p. 44-64, 2016. DOI: https://doi.org/10.5585/riae.v15i1.2168.

GUO, H.; YANG, Z.; HUANG, R.; GUO, A. The digitalization and public crisis responses of small and medium enterprises: Implications from a COVID-19 survey. Frontiers of Business Research in China, Beijing, v. 14, n. 1, p. 1-25, 2020. DOI: https://doi.org/10.1186/s11782020-00087-1.

HAAPANEN, L.; HURMELINNA, P.; NIKILLA, S.; PAAKKOLANVAARA, P. The function-specific microfoundations of dynamic capabilities in cross-border mergers and acquisitions. International Business Review, United Kingdom, v. 28, n. 4, p. 766- 784, 2019. DOI: https://doi.org/10.1016/j.ibusrev.2019.03.002.

HAARHAUS, T.; LIENING, A. Building dynamic capabilities to cope with environmental uncertainty: The role of strategic foresight. Technological Forecasting and Social Change, United States, v. 155, 2020. DOI: https://doi.org/10.1016/j.techfore.2020.120033.

HELFAT, C. E.; PETERAF, M.; TEECE, D.; WINTER, S. G.; FINKELSTEIN, S.; MITCHELL, W.; SINGH, H. Dynamic Capabilities: Understanding Strategic Change in Organizations. 1. ed. Oxford, UK: Blackwell Publishing, 2007.

HELFAT, C. E.; MARTIN, J. A. Dynamic Managerial Capabilities: Review and Assessment of Managerial Impact on Strategic Change. Journal of Management, United States, v. 41, n. 5, p. 1281-1312, 2015. DOI: https://doi.org/10.1177/0149206314561301.

HELFAT, C. E.; PETERAF, M. A. Managerial cognitive capabilities and the microfoundations of dynamic capabilities. Strategic Management Journal, Chicago, v. 36, n. 6, p. 831-850, 2015. DOI: https://doi.org/10.1002/smj.2247.

HERMAWATI, A. The implementation of dynamic capabilities for SMEs in creating innovation. Journal of Workplace Learning, England, v. 32, n. 3, p. 199-216, 2020. DOI: https://doi.org/10.1108/JWL-06-2019-0077.

KEOWN-MCMULLAN, C. Crisis: When does a molehill become a mountain? Disaster Prevention and Management: An International Journal, United Kingdom, v. 6, n. 1, p. 4-10, 1997. DOI: https://doi.org/10.1108/09653569710162406.

KINDSTRÖM, D.; KOWALKOWSKI, C.; SANDBERG, E. Enabling service innovation: A dynamic capabilities approach. Journal of Business Research, New York, v. 66, n. 8, p. 1063-1073, 2013. DOI: https://doi.org/10.1016/J.JBUSRES.2012.03.003.

KRAUS, S.; HARMS, R.; SCHWARZ, E. Strategic business planning and success in small firms. International Journal of Entrepreneurship and Innovation Management, London, v. 8, n. 4, p. 381-396, 2008. DOI: https://doi.org/10.1504/IJEIM.2008.022311.

KUCKERTZ, A.; BRANDLE, A.; GAUDIG, A.; HINDERER, S. Startups in times of crisis - A rapid response to the COVID-19 pandemic. Journal of Business Venturing Insights, Amsterdam, $v$. 13, 2020. DOI: https://doi.org/10.1016/j.jbvi.2020.e00169. 
LIMA, E. Estratégia de pequenas e médias empresas: uma revisão. REGE Revista de Gestão, São Paulo, v. 17, n. 2, p. 169-187, jan. 2010. DOI: https://doi.org/10.5700/rege393.

LÓPEZ, S. V. Competitive advantage and strategy formulation. The key role of dynamic capabilities. Management Decision, United Kingdom, v. 43, n. 5, p. 661-669, 2005. DOI: https://doi.org/10.1108/00251740510597699.

MAHRINGER, C. A.; RENZL, B. Entrepreneurial initiatives as a microfoundation of dynamic capabilities. Journal of Accounting and Organizational Change, United Kingdom, v. 14, n. 1, p. 61-79, 2018. DOI: https://doi.org/10.1108/JAOC-11-2016-0066.

MARANZATO, F. P.; SALERNO, M. S. Integration between research and development: A dynamic capabilities perspective. RAE Revista de Administração de Empresas, São Paulo, v. 58, n. 5, p. 460-474, 2018. DOI: https://doi.org/10.1590/s0034-759020180503.

MORALES, A. J. R.; GALLEGO, V.; ANTEZANA, J. P. E.; MENDEZ, C. A. COVID-19 in Latin America: The implications of the first confirmed case in Brazil. Travel Medicine and Infectious Disease, United Kingdom, v. 35, 2020. DOI: https://doi.org/10.1016/j.tmaid.2020.101613.

MORALES-RUBIANO, M. E.; ORTIZ-RIAGA, C.; DUQUE-OROZCO, Y. V.; PLATA-PACHECO, P. A. Estrategias para fortalecer capacidades dinámicas de innovación: una visión desde las micro y pequeñas empresas. Ciencia, docencia y tecnología, Argentina, v. 27, n. 53, p. 205-233, 2016.

NICOLA, M.; ALSAFI, Z.; SOHRABI, C.; KERWAN, A.; AL-JABIR, A.; IOSIFIDIS, C.; AGHA, M.; AGHA, R. The socio-economic implications of the coronavirus pandemic (COVID-19): A review. International Journal of Surgery, London, v. 78, p. 185-193, 2020. DOI: https://doi.org/10.1016/j.ijsu.2020.04.018.

ORGANIZAÇÃO PAN-AMERICANA DA SAÚDE (OPAS). Folha informativa COVID-19 Escritório da OPAS e da OMS no Brasil. Disponível em: https://www.paho.org/pt/covid19. Acesso em: 03 out. 2020.

ORGANIZAÇÃO MUNDIAL DA SAÚDE (OMS). Boletim Epidemiológico 05 COE-COVID-19. Disponível em: https://coronavirus.saude.gov.br/boletins-epidemiologicos. Acesso em: 13 abr. 2020.

PRIEM, R. L.; BUTLER, J. E. Is the Resource-Based "View" a Useful Perspective for Strategic Management Research? The Academy of Management Review, Chicago, v. 26, n. 1, p. 22 , 2001. DOI: https://doi.org/10.2307/259392.

RIBEIRO, H. C. M.; CORREA, R.; DE SOUZA, M. T. S. Perfil e evolução do tema pequenas e médias empresas em periódicos brasileiros: uma análise bibliométrica. Revista Gestão Organizacional (RGO), Santa Catarina, v. 5, n. 2, p. 242-258, 2012. DOI: https://doi.org/10.22277/rgo.v5i2.1400. 
SAEB, T.; LIEN, L.; FOSS, N. J. What Drives Business Model Adaptation? The Impact of Opportunities, Threats and Strategic Orientation. Long Range Planning, London, v. 50, n. 5, p. 567-581, 2017. DOI: https://doi.org/10.1016/j.Irp.2016.06.006.

SCHERER, J. Aplicação das capacidades dinâmicas para Inovação: identificação das rotinas associadas ao Processo de inovação em uma empresa de grande Porte. Revista Ingeniería Industrial, Chile, v. 16, n. 2, p. 129-140, 2017. DOI:

https://doi.org/10.22320/S07179103/2017.08.

SCHNEIDER, A. B.; CARNEIRO, M. L.; SERRA, F. A. R.; FERREIRA, M. P. Estratégia competitiva: Michael Porter 30 anos depois. Revista de Administração da UFSM, Santa Maria, v. 2, n. 2, p. 298-326, mai./ago., 2009. DOI: https://doi.org/10.5902/198346591558.

SHARMA, P.; LEUNG, T.Y.; KINGSHOTT, R.P. J.; DAVCIK, N. S.; CARDINALI, S. Managing uncertainty during a global pandemic: An international business perspective. Journal of Business Research, New York, v. 116, p. 188-192, 2020. DOI: https://doi.org/10.1016/j.jbusres.2020.05.026.

SINGH, R. K.; GARG, S. K.; DESHMUKH, S. G. Strategy development by SMEs for competitiveness: a review. Benchmarking: An International Journal, United Kingdom, v. 15, p. 525-547, 2008. DOI: https://doi.org/10.1108/14635770810903132.

SOHRABI, C.; ALSAFI, Z.; O'NEILL, N.; KHAN, M.; KERWAN, A.; AL-JABIR, A.; IOSIFIDIS, C.; AGHA, R. World Health Organization declares global emergency: A review of the 2019 novel coronavirus (COVID-19). International Journal of Surgery, London, v. 76, p. 71-76, 2020. DOI: https://doi.org/10.1016/j.ijsu.2020.02.034.

SOUZA, L. O.; BRITO, P. F.; ALVARELI, L. V. G. Empresa familiar e a importância do planejamento para o processo sucessório. Janus, São Paulo, v. 8, n. 13, p. 45-57, jan./jun., 2011.

SPINELLI, A.; PELLINO, G. COVID-19 pandemic: perspectives on an unfolding crisis. British Journal of Surgery, London, v. 107, n. 7, p. 785-787, 2020. DOI:

https://doi.org/10.1002/bjs.11627.

SPURK, D.; STRAUB, C. Flexible employment relationships and careers in times of the COVID19 pandemic. Journal of Vocational Behavior, Florida, v. 119, p. 1-14, 2020. DOI: https://doi.org/10.1016/j.jvb.2020.103435.

TEECE, D. J. Explicating dynamic capabilities: The nature and microfoundations of (sustainable) enterprise performance. Strategic Management Journal, Chicago, v. 28, n. 13, p. 1319-1350, 2007. DOI: https://doi.org/10.1002/smj.640.

TEECE, D. J.; PISANO, G.; SHUEN, A. Dynamic Capabilities and Strategic Management. Strategic Management Journal, Chicago, v. 18, n. 7, p. 509-533, 1997. DOI: https://doi.org/10.1142/9789812796929_0003. 
TEECE, D. J.; LEIH, S. Uncertainty, Innovation, and Dynamic Capabilities: An Introduction. California Management Review, California, v. 58, n. 5, p. 5-12, 2016. DOI: https://doi.org/10.1525/cmr.2016.58.4.5.

VARGO, J.; SEVILLE, E. Crisis strategic planning for SMEs: Finding the silver lining. International Journal of Production Research, London, v. 49, n. 18, p. 5619-5635, 2011. DOI: https://doi.org/1080/00207543.2011.563902.

VILLAR, E. G.; WALTER, S. A.; BRAUM, L. M. S. Da Estratégia Clássica à Estratégia como Prática: Uma Análise das Concepções de Estratégia e de Estrategistas. Revista IberoAmericana de Estratégia, São Paulo, v. 16, n. 01, p. 08-21, jan./mar., 2017. DOI: https://doi.org/10.5585/riae.v16i1.2409.

WAN, W. P.; YIU, D. W. From crisis to opportunity: Environmental jolt, corporate acquisitions, and firm performance. Strategic Management Journal, Chicago, v. 30, n. 7, p. 791-801, 2009. DOI: https://doi.org/10.1002/smj.744.

WANG, C. L.; AHMED, P. K. Dynamic capabilities: A review and research agenda. International Journal of Management Reviews, New Jersey, v. 9, n. 1, p. 31-51, 2007. DOI: https://doi.org/10.1111/j.1468-2370.2007.00201.x.

WANG, Y.; HONG, A., LI, X; GAO, J. Marketing innovations during a global crisis: A study of China firms' response to COVID-19. Journal of Business Research, New York, v. 116, p. 214220, 2020. DOI: https://doi.org/10.1016/j.jbusres.2020.05.029.

WERNERFELT, Birger. A Resource-Based View of the Firm. Strategic Management Journal, Chicago, v. 5, n. 2, p. 171-180, 1984. DOI: https://doi.org/10.1002/smj.4250050207.

WORLD HEALTH ORGANIZATION (WHO). Novel Coronavirus (2019-nCoV) technical guidance. 2020. Disponível em: https://www.who.int/es/dg/speeches/detail/who-directorgeneral-s-remarks-at-the-media-briefing-on-2019-ncov-on-11-february-2020. Acesso em: 13 abr. 2020.

WU, F.; ZHAO, S.; YU, B.; CHEN, Y. M.; WANG, M.; SONG, Z. G.; HU, Y.; TAO, Z. W.; TIAN, J. H.; PEI, Y. Y.; YUAN, M. L.; ZHANG, Y. L.; DAI, F. D; LIU, Y.; WANG, Q. M.; ZHENG, J. J.; XU, L.; HOLMES, E. C.; ZHANG, Y. Z. A new coronavirus associated with human respiratory disease in China. Nature, United Kingdom, v. 579, n. 7798, p. 265-269, 2020. DOI: https://doi.org/10.1038/s41586-020-2008-3.

YIN, R. K. Estudo de Caso: Planejamento e métodos. 5. ed. Porto Alegre: Bookman, 2015.

ZOLLO, M.; WINTER, S. G. Deliberate learning and the evolution of dynamic capabilities. Organization Science, Pennsylvania, v. 13, n. 3, p. 339-351, 2002. DOI: https://doi.org/10.1287/orsc.13.3.339.2780. 